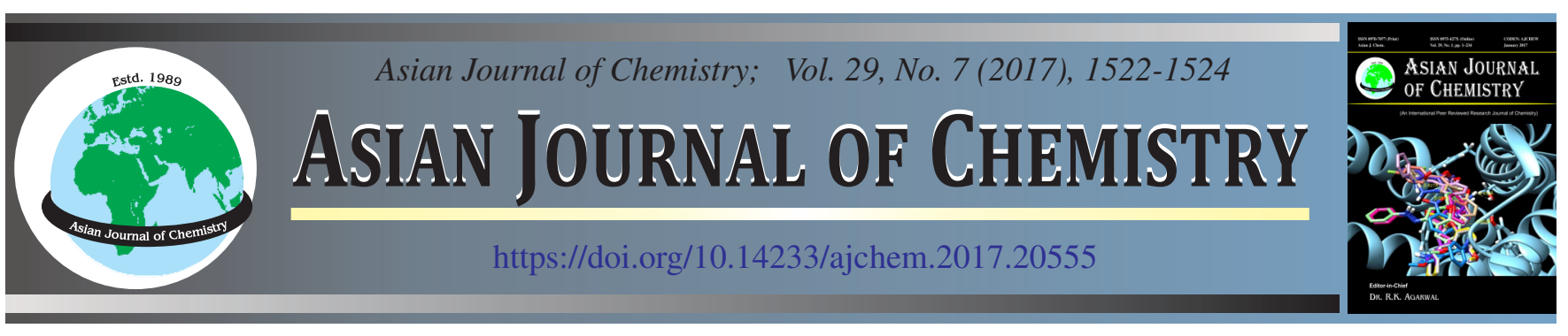

\title{
Flame Atomic Absorption Spectrometric Determination of Trace Quantities of Cadmium from Water Samples
}

\author{
DENIZ SAHIN TAS
}

Department of Chemistry, Faculty of Arts and Sciences, Gazi University, 06500 Ankara, Turkey

Corresponding author: E-mail: dennoka1k@hotmail.com

\begin{abstract}
The influence of some surface-active agents in the medium on determination of ultra-trace quantities of $\mathrm{Cd}^{2+}$ ion by flame atomic absorption spectrometry was investigated. Sodium dodecylsulfate (SDS), cetyltrimethyl ammonium bromide (CTAB) and polyoxyethylene(10) isooctylphenyl ether (TX100) were used as anionic, cationic and non-ionic surface-active agents, respectively. To obtain the optimal concentration of surfactants, the effect of surfactant concentration on the preconcentration of cadmium was investigated by increasing sufactant concentration up to $10 \times$ critical micellar concentration $(\mathrm{CMC})$. The analytical characteristics of the method (e.g., limit of detection, linear range, preconcentration and improvement factors) were obtained. The limits of detection for cadmium are $0.7,0.3$ and $0.3 \mathrm{ppm}$ in presence of SDS, CTAB and TX100, respectively. The method was applied for determination of cadmium in wastewaters.
\end{abstract}

Keywords: Cadmium(II), FAAS, Sodium dodecylsulfate, Cetyltrimethyl ammonium bromide, Triton-X-100.

\section{INTRODUCTION}

Tremendous increase in the use of heavy metals over the past few decades has inevitably led to an increased pollution of metallic substances in natural water and posed serious ecological and health risks.

The toxic heavy metals could also gradually accumulate in the human body through the food chain and cause damage to human health. Cadmium is a well-known toxic and persistent contaminant that is naturally present at very low levels in common aquatic environments [1]. Cadmium can be accumulated in several organs, producing carcinogenic effect [2]. The Food and Agriculture Organization (FAO) of the United Nations and the World Health Organization (WHO) Joint Expert Committee on Food Additives allocated an acceptable daily intake for cadmium from all sources (water, food and air) of 1.0-1.2 $\mu \mathrm{g} \mathrm{kg}^{-1}$ of body weight [3].

According to WHO the upper permissible level of cadmium in unpolluted natural waters are usually below $1 \mu \mathrm{g} / \mathrm{L}$ [4]. For humans, the main sources of cadmium are from daily in-take of water and food. Therefore, sensitive, selective and accurate analytical methods are required for the determination of trace amount of cadmium in en-vironmental, biological and food samples. Several spectral and electrochemical methods have been developed for determination of heavy metal ions [5-11]. Among the spectral methods, flame atomic absorption spectrometry (FAAS) is a more frequently used technique due to its simplicity and lower cost, although this method has a limited sensitivity for cadmium so a preconcentration step is often required to improve the detection limit [12-14]. Hence, combining a preconcentration step prior to FAAS determination is often resorted by various researchers. Many methods have been used for the preconcentration and separation of trace metals from various samples. These include liquid-liquid extraction, co-precipitation, membrane filtration, floatation, cloud point extraction and solid phase extraction [15-22]. Recently, the membrane filtration technique, is slowly becoming the preferred due to the low risk of contamination, the use of environmentally safe reagents and simple methodology. If the metal ions were allowed to be directly collected in the form of metal-complexes or ion-pairs on a membrane filter from an aqueous solution by filtration, this membrane filtration can be used as a rapid and simple concentration and separation technique of pretreatment of samples. the materials of mebrane filter with a strong affinity for hydrophobic species in water are generally useful to retain the species by filtration. Filters made of cellulose are most widely used for separation of trace heavy metal ions in water samples.

The aim of the present study was to investigate the sensitivity and selectivity of atomic absorption determination of trace amount of cadmium by chemical modification.

\section{EXPERIMENTAL}

All the chemicals used were of analytical reagent grade. Deionized water was used throughout the experiments. Stock 
solution of $\mathrm{Cd}(\mathrm{II})$ (1000 $\left.\mathrm{mg} \mathrm{L}^{-1}\right)$ was prepared by dissolving an appropriate amount of $\mathrm{Cd}\left(\mathrm{NO}_{3}\right)_{2} \cdot 4 \mathrm{H}_{2} \mathrm{O}$ (Merck) in deionized water. Working solutions were prepared daily from the stock solution by serial dilution. All standard solutions for FAAS instrument calibration were prepared in mixture of acetoneethanol (1:1). SDS (Merck), CTAB (Aldrich), TX100 (Riedel) were used as supplied. The surfactant stock solutions (2\%, $\mathrm{v} / \mathrm{v}$ ) were prepared by dissolving $2 \mathrm{~mL}$ of concentrated solution in deionized water. A buffer solution ( $\mathrm{pH}: 6.0,1.0 \mathrm{~mol} \mathrm{~L}^{-1}$ ) was prepared by mixing an appropriate amount of acetic acid with sodium acetate solution.

Apparatus and procedure: A Philips PU 9285 model flame atomic absorption spectrometer (FAAS) equipped with an air acetylene burner and chromium hollow cathode lamp was used for the determination of cadmium. The operating conditions were as follows: wavelength: $228.8 \mathrm{~nm}$, lamp current: $4 \mathrm{~mA}$, bandpass: $0.5 \mathrm{~nm}$ and fuel flow rate: $2.0 \mathrm{~L} \mathrm{~min}^{-1}$. Deuterium lamp background correction was used. Determinations were performed triplicate.

\section{RESULTS AND DISCUSSION}

Dependence of concentration readouts on surfactant concentration: The concentrations of $\mathrm{Cd}^{2+}$ have been analyzed via flame atomic absorption spectrometer in the presence of SDS, CTAB or TX100 in seven different concentrations. An ion concentration versus surfactant concentration graph was plotted. All these graphs show the dependence of the measuring results on surfactant concentration, plotted with the experimental data obtained with $\mathrm{Cd}^{2+}-\mathrm{SDS}, \mathrm{Cd}^{2+}-\mathrm{CTAB}$ and $\mathrm{Cd}^{2+}$ TX100 binary systems displayed similar shapes. Fig. 1 comprises the dependence of the apparent concentration of a $\mathrm{Cd}^{2+}$ solution in a concentration of 2.023 ppm on surfactant concentration.

The apparent concentration of $\mathrm{Cd}^{2+}$ is approximately constant with the initial surfactant concentration upto $10 \times$ CMC. The maximum shifts were determined as $0.318,0.315$ and 0.146 ppm SDS, CTAB and TX100, respectively. Therefore, the initial surfactant concentration up to $10 \times \mathrm{CMC}$ is the appropriate value to obtain effective determination of ion via FAAS.

Calibration graphs and regression equations: We have conducted the first systematic studies on the effect of the nature and the concentration of surfactants. Determinations were performed triplicate. In the first step calibration curves were constructed of solutions with additions of the surfactant (Fig. 2; 2). For the preparation of each standard solution $6.0 \times$ $10^{-3} \mathrm{M}$ of micellar reagents and appropriate amounts of the metal ion solution were added to $10 \mathrm{~mL}$ voltametric flask and made up to the mark with double deionized water. The concentration of cadmium was 0.3-3.2 ppm. The absorbances were measured at $228.8 \mathrm{~nm}$, against a reagent blank for cadmium ions. In the next step another calibration curves were constructed with several points for aqueous solutions (Fig. 2; 1) and then the apparent concentration of $\mathrm{Cd}^{2+}$ determined by FAAS versus its actual concentration graph was plotted in the presence of $4.0 \times$ $10^{-3} \mathrm{M}$ surfactant (Fig. 3). The MEUF system is observed to have optimal surfactant to metal (S/M) ratios of 10-400. Therefore, solutions were prepared dissolving $\mathrm{Cd}\left(\mathrm{NO}_{3}\right)_{2} \cdot 4 \mathrm{H}_{2} \mathrm{O}$ and surfactant in deionized water so that $\mathrm{S} / \mathrm{M}$ ratio was 200.

We have shown that all the studied surfactants increase the analytical signal of cadmium. The maximum increase in the cadmium analytical signal is achieved when SDS is added

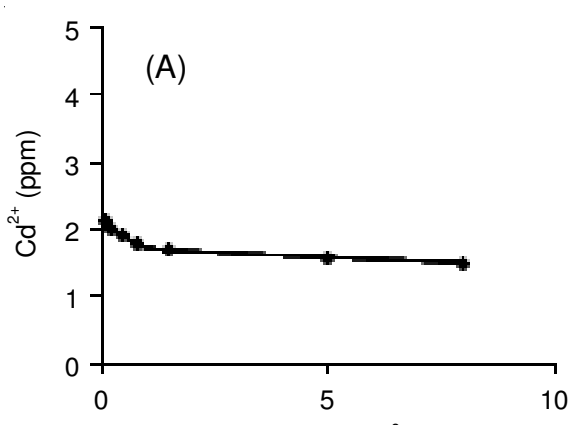

$[S D S] \times 10^{3}$
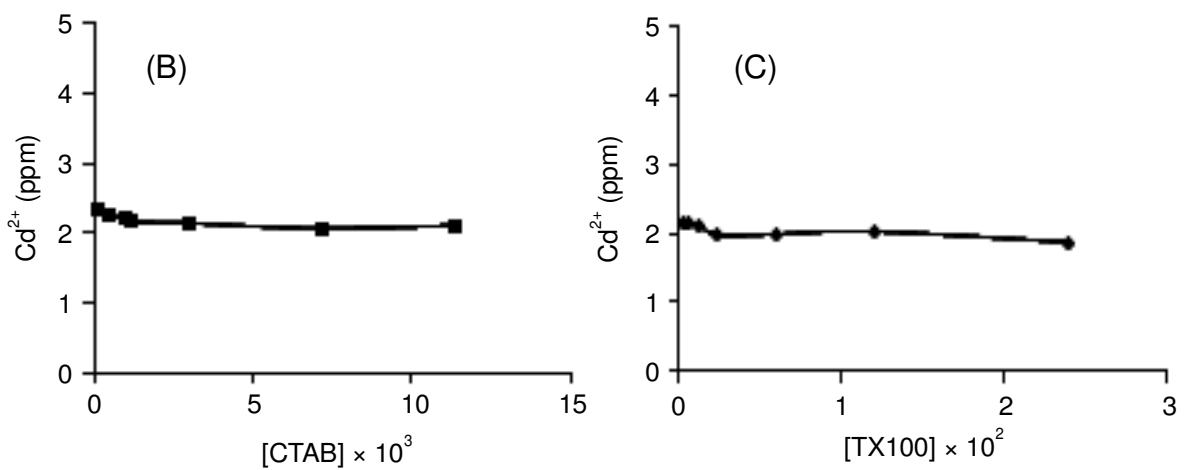

Fig. 1. Dependence of the apparent concentration on surfactant concentration for a $\mathrm{Cd}^{2+}$ solution in a concentration of $2.023 \mathrm{ppm} \mathrm{SDS}$ (A), CTAB (B), TX100 (C)
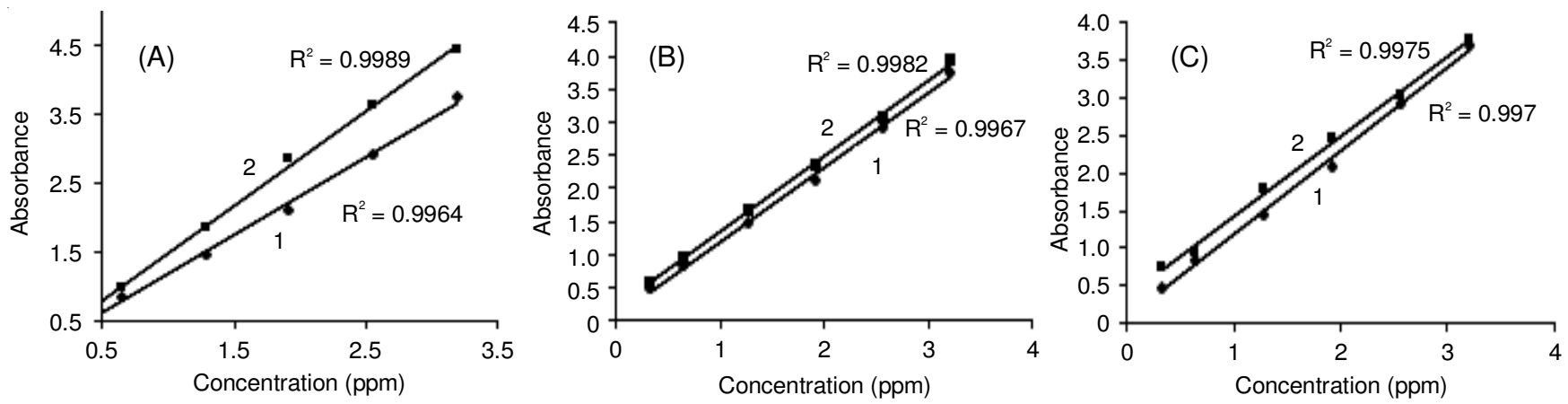

Fig. 2. Calibration curves for aqueous solutions (1) and solutions with additions of the surfactant (2); (A) SDS, (B) CTAB, (C) TX100; $\mathrm{R}^{2}$ is the correlation coefficient 
to the analyte solutions. Here redistribution of the cadmium ions occurs, which leads to their saturation of predominantly small droplets, the number of which is maximum in the CMC region and consequently to an increase in the sensitivity of the atomic absorption determination of cadmium. In this case, the weight fraction of surfactant is $0.2 \mathrm{wt} \%$ or $6.0 \times 10^{-3} \mathrm{~mol} / \mathrm{L}$. Fig. 3 illustrates one of the calibration graphs for $\mathrm{Cd}^{2+}-\mathrm{SDS}$ system, plotted with the results obtained in the presence of $4.0 \times 10^{-3} \mathrm{M}$ SDS. Calibration graphs for the three systems, i.e., $\mathrm{Cd}^{2+}-\mathrm{SDS}, \mathrm{Cd}^{2+}-\mathrm{CTAB}$ and $\mathrm{Cd}^{2+}-\mathrm{TX} 100$ have also been plotted in the same manner. Regression equations representing the straight lines in these graphs, all the regression factors, $\mathrm{R}^{2}$, larger than 0.99. The correlation coefficient of iron is determined 0.9992 when SDS is used as the modifier [23].

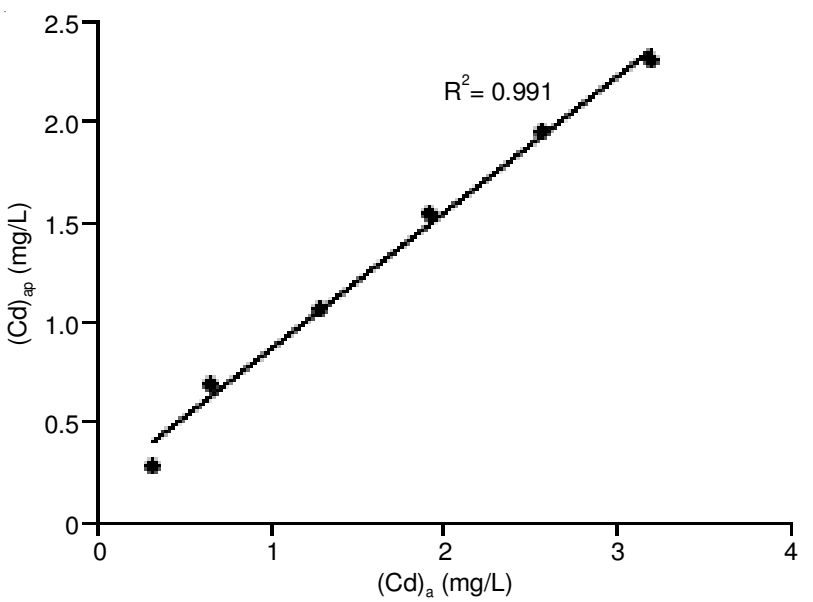

Fig. 3. Dependence of apparent concentration of $\mathrm{Cd}^{2+}$ determined by FAAS, on its actual concentration in the presence of $4.0 \times 10^{-3} \mathrm{M}$ SDS

Effect of foreign elements on analytical signal for cadmium: The effect of foreign metal ions on the determination of $\mathrm{Cd}^{2+}$ by the proposed method was investigated. An ion was considered as interferent, when it caused a variation in the absorbance of the sample greater than $\pm 5 \%$. The following ions did not interfere at determination of $2.023 \mathrm{ppm} \mathrm{Cd}^{2+}: \mathrm{Na}^{+}, \mathrm{K}^{+}$, $\mathrm{Li}^{+}, \mathrm{Mg}^{2+}, \mathrm{Cu}^{2+}, \mathrm{Co}^{2+}, \mathrm{Pb}^{2+}, \mathrm{Ca}^{2+}, \mathrm{Ba}^{2+}, \mathrm{Ni}^{2+}, \mathrm{Sr}^{2+}, \mathrm{Zn}^{2+}, \mathrm{Be}^{2+}$, $\mathrm{Hg}^{2+}, \mathrm{Cr}^{3+}, \mathrm{Fe}^{3+}, \mathrm{Cl}^{-}, \mathrm{Br}^{-}, \mathrm{SO}_{4}{ }^{2-}, \mathrm{NO}_{3}{ }^{-}, \mathrm{PO}_{4}{ }^{3-}, \mathrm{V}(\mathrm{V})$ and $\mathrm{As}(\mathrm{III})$. As the results show large excess amounts of common cations and anions do not interfere on the determination of trace quantities of cadmium [24-26].

Atomic absorption determination of cadmium in water samples: To evaluate the accuracy and precision of the method, it was applied to the determination of cadmium in waste water samples. The results are given in Table-1. The results show that the proposed method is suitable for determination of $\mathrm{Cd}^{2+}$ in such water samples. Water samples were filtered using a 5000 Da pore size membrane filter to remove $\mathrm{Cd}^{2+}$.

TABLE-1

DETERMINATION OF CADMIUM IN WATER SAMPLES

\begin{tabular}{|c|c|c|c|}
\hline \multirow{2}{*}{ Sample } & \multicolumn{2}{|c|}{ Cadmium concentration (ppb) } & \multirow{2}{*}{$\begin{array}{l}\text { Recovery } \\
(\%, \mathrm{n}=3)\end{array}$} \\
\hline & Taken & Found & \\
\hline & - & $5.19 \pm 0.26$ & 96 \\
\hline Wastewater & $\begin{array}{c}5.6 \\
10.0\end{array}$ & $\begin{array}{l}10.49 \pm 0.15 \\
20.45 \pm 0.10\end{array}$ & $\begin{array}{c}98 \\
100\end{array}$ \\
\hline
\end{tabular}

Average of three measurements; Wastewater sample was collected from of battery plant.

\section{Conclusion}

Using SDS as a modifier in flame atomic absorption determination of cadmium in wastewater samples allows us to make the measurements in increasing the sensitivity and selectivity and also lowering the detection limit for cadmium.

\section{REFERENCES}

1. P.J. Wangersky, in ed.: P.J. Wangersky, Intercomparisons and Intercalibrations, Marine Chemistry, Springer-Verlag: Berlin (2000).

2. M.L. Garrido, R.M. Olivas and C. Camara, J. Anal. At. Spectrom., 13, 295 (1998);

https://doi.org/10.1039/A707419K.

3. FAO/WHO Joint Expert Committee on Food Additives, WHO Techical Report Snal. No. 505, p. 32 (1972).

4. World Health Organization (WHO), Guidelines for Drinking-Water Quality, WHO Press: Geneva, edn 3, vol. 1 (2008).

5. I. Oehme and O.S. Wolfbeis, Mikrochim. Acta, 126, 177 (1997); https://doi.org/10.1007/BF01242319.

6. M. Pesavento, G. Alberti and R. Biesuz, Anal. Chim. Acta, 631, 129 (2009); https://doi.org/10.1016/j.aca.2008.10.046.

7. R. Sitko, B. Zawisza and E. Malicka, Trends Analyt. Chem., 37, 22 (2012); https://doi.org/10.1016/j.trac.2012.03.016.

8. X.G. Li, H. Feng, M.R. Huang, G.L. Gu and M.G. Moloney, Anal. Chem., 84, 134 (2012); https://doi.org/10.1021/ac2028886.

9. M.-R. Huang, Y.-B. Ding and X.-G. Li, Analyst, 138, 3820 (2013); https://doi.org/10.1039/C3AN00346A.

10. M.R. Huang, X.W. Rao, X.G. Li and Y.B. Ding, Talanta, 85, 1575 (2011); https://doi.org/10.1016/j.talanta.2011.06.049.

11. X.G. Li, X.L. Ma and M.R. Huang, Talanta, 78, 498 (2009); https://doi.org/10.1016/j.talanta.2008.11.045.

12. A.N. Araújo, R.C.C. Costa and J.L.F.C. Lima, Anal. Sci., 15, 991 (1999); https://doi.org/10.2116/analsci.15.991.

13. I. Karadjova, G. Zachariadis, G. Boskou and J. Stratis, J. Anal. At. Spectrom., 13, 201 (1998); https://doi.org/10.1039/a707256b

14. P. Viñas, I. López-García, M. Lanzón and M. Hernández-Córdoba, J. Agric. Food Chem., 45, 3952 (1997); https://doi.org/10.1021/jf970272u.

15. A Junker-Buchheit and M.J. Witzenbacher, J. Chromatogr. A, 737, 67 (1996);

https://doi.org/10.1016/0021-9673(95)01337-7.

16. J.S. Fritz, Analytical Solid Phase Extraction, Wiley-VCH: New York, edn 1 (1999).

17. M. Ghaedi, A. Shokrollahi, K. Niknam, E. Niknam, A. Najibi and M. Soylak, J. Hazard. Mater, 168, 1022 (2009); https://doi.org/10.1016/j.jhazmat.2009.02.130.

18. M. Ghaedi, A. Shokrollahi, A.H. Kianfar, A.S. Mirsadeghi, A. Pourfarokhi and M. Soylak, J. Hazard. Mater., 154, 128 (2008); https://doi.org/10.1016/j.jhazmat.2007.10.003.

19. M. Ghaedi and M.R. Fathi, Fresenius Environ. Bull., 14, 1158 (2005).

20. M. Soylak and M. Tuzen, J. Hazard. Mater., 152, 656 (2008); https://doi.org/10.1016/j.jhazmat.2007.07.027.

21. A.N. Anthemidis, D.G. Themelis and J.A. Stratis, Talanta, 54, 37 (2001); https://doi.org/10.1016/S0039-9140(00)00620-2.

22. L. Pan, Y.C. Qin, B. Hu and Z.C. Jiang, Chem. Res. Chin. Univ., 23, 399 (2007); https://doi.org/10.1016/S1005-9040(07)60086-5.

23. S.Z. Mohammadi Mobarakeh, M.A. Taher and A. Mostafavi, Can. J. Anal. Sci. Spectrosc., 50, 7 (2005).

24. D. Afzali, M. Taher, A. Mostafavi and S. Mobarakeh, Talanta, 65, 476 (2005); https://doi.org/10.1016/j.talanta.2004.06.027).

25. M.A. Taher, B.K. Puri and R.K. Bansal, Microchem. J., 58, 21 (1998); https://doi.org/10.1006/mchj.1997.1502.

26. A. Shokrollahi, M. Ghaedi, O. Hossaini, N. Khanjari and M. Soylak, J. Hazard. Mater, 160, 435 (2008); https://doi.org/10.1016/j.jhazmat.2008.03.016 